\title{
Research on mechanical behavior of calcined coal gangue cement mortar with different chemical activators
}

\author{
Bingke Qin ${ }^{1,2, a}$, Yonghua Ji ${ }^{1, b}$, Zhiling Bai ${ }^{1, c}$, Qingkao Zhao ${ }^{1, d}$
}

${ }^{1}$ School of Chemistry and materials Engineering, Liupanshui Normal University, Liupanshui, China

${ }^{2}$ College of Materials and Metallurgy, Guizhou University, Guiyang, China

aqinbingke@126.coml, bhaizhigong@126.com, czhilingbai@126.com, dkr2012@126.com

\section{Keywords: Coal gangue; Cement mortar; Activator; Mechanical properties}

Abstract. Coal gangue as admixture cement gelled material preparation, the preparation process of coal gangue calcined temperature of $600^{\circ} \mathrm{C}$, using common $\mathrm{P} \bullet \mathrm{O} 32.5 \mathrm{R}$ ordinary Portland cement, add $15 \%$ of fly ash and $1 \%$ of poly (carboxylic acid water reducing agent, chemical excitation agent with a purity of $99.9 \% \mathrm{Ca}(\mathrm{OH})_{2}, \mathrm{Na}_{2} \mathrm{SO}_{4}$ and $\mathrm{CaCl}_{2}$, preparation of cement mortar specimens after standard curing, compressive strength, flexural mechanical properties were tested. The results showed that the excitation effect of three kinds of excitant was: $\mathrm{Ca}(\mathrm{OH})_{2}>\mathrm{Na}_{2} \mathrm{SO}_{4}>\mathrm{CaCl}_{2}$. The optimum content of the excitation agent $\mathrm{Ca}(\mathrm{OH})_{2}$ was $3 \%$, and the sample $28 \mathrm{~d}$ obtained the maximum compressive strength of $26.47 \mathrm{MPa}$.

\section{Introduction}

Coal gangue is one of the wastes produced in the process of coal washing, and it is the main impurity in the raw coal. The main components of coal gangue are quartz, kaolinite, and a small amount of illite, pyrite and amorphous carbon. Liupanshui area is one of the largest coal resources bases in South China, where coal gangue is discharged every year as many as millions of tons. The stacking of coal gangue will become a waste rock hill and take up a lot of land. When the temperature is high in summer, the waste rock is prone to spontaneous combustion. After the spontaneous combustion, a large amount of waste gas is produced, which causes serious pollution to the atmosphere. The heavy metal ions seeping out of the gangue will cause pollution to the local soil and water resources [1-3]. After the pollution of coal gangue to the environment, it will affect the healthy development of the ecological environment for a long time. Therefore, it has become one of the most important directions of coal solid waste research that how to reuse coal gangue to reuse resources.

According to different coal forming age and mineral composition, the physical and chemical properties of coal gangue vary greatly. Some coal gangue carbon content and fragile minerals more, hardness is very small; some coal gangue quartz content is very large, hardness is very big. In the process of coal gangue utilization, the separation can be carried out according to the difference of mechanical properties. After being calcined and activated, the friable gangue can be used as the admixture of cement cementing material. The coal gangue with high hardness can be extracted from white carbon and other chemical raw materials. It can also be used as the aggregate of concrete after washing.

Coal gangue should be used in cement concrete, which is one of the ways of resource utilization. Coal gangue should be activated before use, otherwise it will have bad influence on the performance of cement cementing material. There are many methods for coal gangue activation, mainly including three kinds of mechanical activation, thermal activation and chemical activation, among which thermal activation and chemical activation are often used. Chemical activation is the addition of chemical activators to coal gangue to stimulate the cementitious properties of coal gangue, thus partially replacing cement as admixture to use $[4,5]$. In this study, in order to maximize the resource utilization of coal gangue, the coal gangue from Liupanshui area was reasonable after sorting, after calcination, adding chemical activator, the coal gangue cement should be used for cementitious material, and provide some technical reference for solving the pollution of coal gangue and the application of local area. 


\section{Experiment}

Cement with ordinary portland cement on the local market, the mark of $\mathrm{P} \cdot \mathrm{O} 32.5$ cement; sand as local stone sand $5 \mathrm{~mm}$, mud content is less than 0.5\%. Coal gangue comes from Eagle mountain mine in Liupanshui. The fly ash is made of fly ash from Wang Jia Shan power plant. Polycarboxylate superplasticizer is used in water reducing agent. The purity of activator $\mathrm{Ca}(\mathrm{OH})_{2}, \mathrm{Na}_{2} \mathrm{SO}_{4}$ and $\mathrm{CaCl}_{2}$ is $99.9 \%$. Water is placed more than $24 \mathrm{~h}$ of tap water.

Coal gangue after self medium separator separates the poor mechanical property of coal gangue, better mechanical property of coal gangue after washing the precipitate after drying and poor mechanical properties of coal gangue in XL-1 furnace in calcination, calcination temperature of $600^{\circ} \mathrm{C}$ [5], the calcined coal gangue through ball milling, grinding fineness is less than 200 powder, as admixture according to $50 \%$ cement quality in cement mortar. The ratio of water to binder is 0.36 , the content of fly ash is $15 \%$, and the content of polycarboxylate superplasticizer is $1 \%$. The water reducing agent is added into cement mortar according to the percentage of cement and gangue. The amount of activator is the percentage of added coal gangue. Try to measure the strength, through excitation of coal gangue in different dosage (mass fraction) mixed into cement mortar, and according to GB/T 17617 - 1999 "cement mortar strength test method (ISO method)" for molding and curing specimens using WAW-600C type universal testing machine, test of cement the mechanical properties of the specimen sand.

\section{Results and discussion}

The activation effect of $\mathrm{Ca}(\mathrm{OH})_{2}$ on calcined coal gangue cements mortar. The mechanical properties of $\mathrm{Ca}(\mathrm{OH})_{2}$ as the activator of calcined coal gangue cement mortar are shown in Table 1 and table 2. Table 1 is the test result of compressive strength of specimens. Table 2 shows the flexural strength test results of specimens. As can be seen from table 1, the addition of activator $\mathrm{Ca}(\mathrm{OH})_{2}$ significantly improves the early compressive strength of coal gangue cement mortar, and has a certain increase in the later strength. With the increase of the content of activator $\mathrm{Ca}(\mathrm{OH})_{2}$, the compressive strength of the sample decreases at the later stage. When the content of $\mathrm{Ca}(\mathrm{OH})_{2} \mathrm{was} 3 \%$, the compressive strength reached the maximum at 3 and 28 days, and the maximum values were 14.52MPa and 26.47MPa respectively.

\begin{tabular}{cccccc}
\multicolumn{6}{c}{ Table 1. The effect of activator $\mathrm{Ca}(\mathrm{OH})_{2}$ on compressive strength of cement mortar } \\
\hline $\mathrm{Ca}(\mathrm{OH})_{2}$ concent $(\%)$ & 0 & 3 & 6 & 9 & 12 \\
\hline $3 \mathrm{~d}(\mathrm{MPa})$ & 6.96 & 14.52 & 11.49 & 9.52 & 10.32 \\
$7 \mathrm{~d}(\mathrm{MPa})$ & 9.46 & 18.51 & 15.34 & 14.55 & 13.51 \\
$28 \mathrm{~d}(\mathrm{MPa})$ & 21.15 & 26.47 & 25.26 & 24.53 & 23.13 \\
\hline
\end{tabular}

Table 2. The effect of activator $\mathrm{Ca}(\mathrm{OH})_{2}$ on flexural strength of cement mortar

\begin{tabular}{cccccc}
\hline $\mathrm{Ca}(\mathrm{OH})_{2}$ concent $(\%)$ & 0 & 3 & 6 & 9 & 12 \\
\hline $3 \mathrm{~d}(\mathrm{MPa})$ & 2.17 & 2.45 & 2.34 & 2.14 & 2.01 \\
$7 \mathrm{~d}(\mathrm{MPa})$ & 3.80 & 3.71 & 3.48 & 3.34 & 3.26 \\
$28 \mathrm{~d}(\mathrm{MPa})$ & 7.12 & 9.02 & 8.57 & 8.12 & 7.41 \\
\hline
\end{tabular}

The effect of $\mathrm{Ca}(\mathrm{OH})_{2}$ on the early flexural strength of calcined coal gangue cement paste was not significant, and the flexural strength in the later stage was slightly increased compared with that in the sample without adding the activator. When the content of $\mathrm{Ca}(\mathrm{OH})_{2}$ was $3 \%$, the flexural strength of specimens at 3 and 28 days were $2.45 \mathrm{MPa}$ and $9.02 \mathrm{MPa}$ respectively, and reached the maximum. Comprehensive analysis shows that when $\mathrm{Ca}(\mathrm{OH})_{2}$ is used as activator, the activation effect of calcined gangue will be the best when adding $3 \%$. 
The activation effect of $\mathrm{Na}_{2} \mathrm{SO}_{4}$ on calcined coal gangue cements mortar. The influence of $\mathrm{Na}_{2} \mathrm{SO}_{4}$ as activator on mechanical properties of cement mortar is shown in Table 3 and table 4. Table 3 show that when the activator $\mathrm{Na}_{2} \mathrm{SO}_{4}$ is less than $6 \%$, the compressive strength of specimens increases significantly, and the strength increases slightly at 28 days. When the content of $\mathrm{Na}_{2} \mathrm{SO}_{4}$ exceeds $6 \%$, the later strength of the sample will decrease. When $\mathrm{Na}_{2} \mathrm{SO}_{4}$ is $3 \%$, the strength of the sample reaches the maximum at 28 days, and the maximum is $23.59 \mathrm{MPa}$. This result may be related to the fact that $\mathrm{Na}_{2} \mathrm{SO}_{4}$ is not fully stimulated during the cement hydration process and the gangue is not fully stimulated [6].

Table 4 is the effect of the amount of activator $\mathrm{Na}_{2} \mathrm{SO}_{4}$ on the flexural strength of cement mortar. It can be seen from the table that the addition of activator $\mathrm{Na}_{2} \mathrm{SO}_{4}$ can weaken the flexural strength of cement mortar. When the addition amount is less than $6 \%$, the flexural strength of the sample decreases, but the decrease is not significant. When the dosage of the activator is more than $6 \%$, the flexural strength of the specimen decreases greatly compared with that without the addition agent $\mathrm{Na}_{2} \mathrm{SO}_{4}$. Comprehensive experimental results show that the amount of activator $\mathrm{Na}_{2} \mathrm{SO}_{4}$ should not be too much, and adding less than $3 \%$ is more appropriate.

Table 3. Effect of activator $\mathrm{Na}_{2} \mathrm{SO}_{4}$ addition on compressive strength of cement mortar

\begin{tabular}{cccccc}
\hline $\mathrm{Na}_{2} \mathrm{SO}_{4}$ concent $(\%)$ & 0 & 3 & 6 & 9 & 12 \\
\hline $3 \mathrm{~d}(\mathrm{Mpa})$ & 6.96 & 11.23 & 8.51 & 6.12 & 5.17 \\
$7 \mathrm{~d}(\mathrm{MPa})$ & 9.46 & 14.54 & 12.54 & 7.92 & 8.49 \\
$28 \mathrm{~d}(\mathrm{MPa})$ & 21.15 & 23.59 & 21.37 & 17.52 & 13.58 \\
\hline
\end{tabular}

Table4. Effect of the amount of activator $\mathrm{Na}_{2} \mathrm{SO}_{4}$ on flexural strength of cement mortar

\begin{tabular}{cccccc}
\hline $\begin{array}{c}\mathrm{Na}_{2} \mathrm{SO}_{4} \\
\text { concent }(\%)\end{array}$ & 0 & 3 & 6 & 9 & 12 \\
\hline $3 \mathrm{~d}(\mathrm{MPa})$ & 2.17 & 2.46 & 2.09 & 1.82 & 1.71 \\
$7 \mathrm{~d}(\mathrm{MPa})$ & 3.80 & 3.42 & 2.49 & 2.37 & 2.02 \\
$28 \mathrm{~d}(\mathrm{MPa})$ & 7.12 & 5.48 & 5.25 & 5.32 & 5.31 \\
\hline
\end{tabular}

The activation effect of $\mathbf{C a C l}_{2}$ on calcined coal gangue cements mortar. Table 5 is the test result of the compressive strength of calcined coal gangue cement mortar with $\mathrm{CaCl}_{2}$ as an activator. Table 6 shows the flexural strength test results of the sample. Table 5 test results show that the addition of activator $\mathrm{CaCl}_{2}$ significantly improves the early compressive strength of coal gangue cement mortar. When the $\mathrm{CaCl}_{2}$ content is $3 \%$, the compressive strength of the sample reaches 3 12.53MPa. With the increase of $\mathrm{CaCl}_{2}$ content of the activator, the early compressive strength increases slightly. $\mathrm{CaCl}_{2}$ has little effect on the later strength of the sample. When the content of activator $\mathrm{CaCl}_{2}$ is $3 \%$, the compressive strength of the sample reaches the maximum at 28 days, and the maximum value is $22.31 \mathrm{MPa}$.

Table 5. The effect of activator $\mathrm{CaCl}_{2}$ addition on compressive strength of cement mortar

\begin{tabular}{cccccc}
\hline $\mathrm{CaCl}_{2}$ concent $(\%)$ & 0 & 3 & 6 & 9 & 12 \\
\hline $3 \mathrm{~d}(\mathrm{MPa})$ & 6.96 & 12.53 & 11.51 & 10.29 & 9.86 \\
$7 \mathrm{~d}(\mathrm{MPa})$ & 9.46 & 13.42 & 12.28 & 11.42 & 10.54 \\
$28 \mathrm{~d}(\mathrm{MPa})$ & 21.15 & 22.31 & 20.45 & 19.91 & 18.62 \\
\hline
\end{tabular}

Table. 6 shows that the addition of activator $\mathrm{CaCl}_{2}$ has little effect on the early flexural strength of calcined coal gangue cement mortar, and has a decreasing effect on the flexural strength at the later stage. When the content of $\mathrm{CaCl}_{2}$ was $6 \%$, the flexural strength of specimens was the maximum at 3 days, and the maximum value was $3.39 \mathrm{MPa}$. When the content of $3 \%$ was added to $\mathrm{CaCl}_{2}$, the maximum flexural strength at 28 days was $5.69 \mathrm{MPa}$. Comprehensive experimental results show that when $\mathrm{CaCl}_{2}$ is used as activator, the compressive strength of calcined coal gangue cement will be 
improved at the addition of about $3 \%$.

Table 6.The effect of the amount of activator $\mathrm{CaCl}_{2}$ on flexural strength of cement mortar

\begin{tabular}{cccccc}
\hline $\mathrm{CaCl}_{2}$ concent $(\%)$ & 0 & 3 & 6 & 9 & 12 \\
\hline $3 \mathrm{~d}(\mathrm{MPa})$ & 2.17 & 2.18 & 3.39 & 2.24 & 2.01 \\
$7 \mathrm{~d}(\mathrm{MPa})$ & 3.80 & 2.72 & 3.78 & 3.61 & 2.42 \\
$28 \mathrm{~d}(\mathrm{MPa})$ & 7.12 & 5.69 & 5.57 & 5.36 & 5.64 \\
\hline
\end{tabular}

\section{Conclusions}

Through the experimental test of different activator $\mathrm{Ca}(\mathrm{OH})_{2}, \mathrm{Na}_{2} \mathrm{SO}_{4}$ and $\mathrm{CaCl}_{2}$, the large amount of calcined coal gangue cement mortar activation effect, the activation influence from big to small order is: $\mathrm{Ca}(\mathrm{OH})_{2}>\mathrm{Na}_{2} \mathrm{SO}_{4}>\mathrm{CaCl}_{2}$. The optimum dosage of activator $\mathrm{Ca}(\mathrm{OH})_{2}$ is $3 \%$. The maximum compressive strength of the sample $28 \mathrm{~d}$ is $26.47 \mathrm{MPa}$, and the flexural strength reaches $9.02 \mathrm{MPa}$. The dosage of activator $\mathrm{Na}_{2} \mathrm{SO}_{4}$ is less than $3 \%$, which is suitable and should not be too much. When the amount of $\mathrm{Na}_{2} \mathrm{SO}_{4}$ addition is about $3 \%$, the early strength of gangue cement mortar can be improved. Activator $\mathrm{CaCl}_{2}$ has little influence on the strength of gangue cement paste. $\mathrm{CaCl}_{2}$ can significantly improve the early compressive strength of coal gangue cement mortar. When the $\mathrm{CaCl}_{2}$ content is $3 \%$, the sample of the 3 day compressive strength reached $12.53 \mathrm{MPa}$.

\section{Acknowledgements}

This study has been supported by the Guizhou provincial science and technology department joint fundation (Qiankehe Jzi LKLS [2013]19); Guizhou province ordinary college innovation team of mineral processing and comprehensive utilization of scientific and technological (Qianjiaohe Talent team zi[2015] 69); Guizhou provincial department of education fund project (QianjiaoheKYzi[2016]102); Guizhou province ordinary college innovation team of coal solid waste recycling technology (Qianjiaohe Talent team zi [2014]46).

\section{References}

[1] Dong Zuochao, Xia Junwu: Construction and Building Materials Vol.100 (2015),P.63-69.

[2] Chuncai Zhou, Guijian Liu, Shengchun Wu: Chemosphere Vol. 95 (2014),P. 274-280.

[3] Li Li Hu. Materials Science Forum Vol.4269 (2016),P.96-104.

[4] Xiujun Guo: Coal engineering Vol.49(2016),P.74-76. In Chinese.

[5] Deshun Kong,Zhi Li,Jiaxin Fan et al: Coal Engineering Vol.7(2013),P.99-101. In Chinese.

[6] Jinman Wang, Qian Qin, Sijia Hu: Journal of Cleaner Production Vol.(2015),P.1-8. 